\title{
BÓSNIA-HERZEGÓVINA: UMA ANÁLISE GEOPOLÍTICA
}

\author{
Cecilia Antakly de Mello \\ Gilberto Bercovici \\ Alunos do Curso de Graduação da Faculdade de Direito da USP
}

\begin{abstract}
Resumo:
O presente artigo tem por objetivo delinear uma visão sobre os acontecimentos recentes na Bósnia-Herzegóvina. O tema inicial é uma análise histórica da Iugoslávia, incluindo a tentaiva de Tito de manter a unificação do país. $\mathrm{O}$ trabalho segue nas considerações sobre o problema de minoria étnica e de um relato da guerra na Bósnia até julho de 1994. Finaliza com um estudo sobre os interesses geopolíticos das nações vizinhas e das potências européias na lugoslávia e um prognóstico do desenrolar da guerra.
\end{abstract}

\begin{abstract}
:
The purpose of this article is to delineate a view on the recent occurrences in Bosnia-Herzegovia. The initial point is a historical analysis of Iugoslavia, including Tito's attempt to keep the country's unity. The work following some considerations about the ethnic minority question and a war report in Bosnia until july 1994. Finally, we present the conclusion with a study about the geopolitical interests of neighbour nations and european powers in Iugoslavia and a war's development prognostic.
\end{abstract}

Para que possamos compreender os conflitos que ocorrem atualmente na desagregada Iugoslávia, é necessário lançar um olhar histórico e geopolítico sobre a região. Apenas desse modo poderemos tentar interpretar os acontecimentos contemporâneos e, talvez, prognosticar a respeito dos possiveis desenlaces para 0 processo de transição ora vivido.

\section{Resumo Geográfico}

A Bósnia-Herzegóvina é uma das seis repúblicas da antiga Iugoslávia. Apresenta uma área de $51.129 \mathrm{~km}^{2}$ e uma população de 
aproximadamente 4 milhões de habitantes. É limitada a oeste e ao sul pela Croácia, ao norte e nordeste pela Sérvia e a leste por Montenegro. Existe um pequeno acesso ao Mar Adriático de apenas $20 \mathrm{~km}$ de extensão, porém sem portos marítimos relevantes.

O terreno é predominantemente montanhoso, coberto por florestas de pinheiros e carvalhos, com vales férteis e aproveitáveis. A área agriculturável é de aproximadamente $50 \%$ da área total. A economia da República é predominantemente agrícola, com destaque para os cereais, o tabaco, a beterraba e a batata. As indústrias principais são as do aço, do couro, de cigarros e de açúcar.

Geograficamente a República subdivide-se em duas áreas distintas: ao norte a Bósnia, cujo nome deriva do Rio Bosna, e ao sul a Herzegóvina, cujo nome deriva de Herceg, ou seja Duque, em servo-croata. A palavra Herzegóvina tem o significado aproximado de Ducado.

Etnicamente a população da Bósnia-Herzegóvina é fortemente heterogênea e está aí o foco de seus problemas. Aproximadamente 1/3 da população é sérvia, ou seja, eslavos de religião cristã-ortodoxa, de idioma servo-croata grafado com o alfabeto cirílico, com fortes ligações culturais com a região de Belgrado na Sérvia e, através desta, com a Rússia e a Ucrânia. Outra parcela da população, representando igualmente cerca de $1 / 3$, é croata, também eslava, porém cristãcatólica; embora falando o mesmo idioma servo-croata, utiliza-se de gramática diversa e do alfabeto latino. Os bósnios-croatas são eslavos mais germanizados, com ligações culturais com a região de Zagreb na Croácia e através desta com a vizinha Eslovênia e com a Áustria. O restante da população, ou seja, o 1/3 remanescente é muçulmana, se não de prática, pelo menos de origem. A comunidade bósnia muçulmana representa o vestígio étnico-cultural mais ocidental do outrora vasto Império Otomano. Embora se utilizem do mesmo idioma servocroata, o Islamismo orienta as ligações culturais dos bósnios muçulmanos na direção da Turquia e da Albânia.

\section{Resumo Histórico}

À época da dominação romana, a região era habitada por tribos ilírias, povo de origem indo-européia que se espalhava pela região balcânica. A Bósnia fez parte, por muitos séculos, das províncias romanas da Ilíria e da Panônia. 
Após um período caótico, quando a região foi passagem das tribos teutônicas que destruíram o Império Romano, teve início no século VII o povoamento eslavo. Os eslavos têm em comum seus idiomas, todos eles pertencentes a uma mesma família linguística do tronco indo-europeu. São originários de algum ponto indefinido da Europa Central e, segundo a lenda, são todos descendentes de três irmãos: Czech, Liakh e Rus, os quais teriam migrado respectivamente para as regiões de Praga, Varsóvia e Moscou.

Embora tendo fortes ligações com o reino medieval da Sérvia, a Bósnia já era descrita como uma entidade política diferente no século $\mathrm{X}$. No século XII a Bósnia havia se transformado num protetorado húngaro. Em 1137, por exemplo, Laszlo II, Rei da Bósnia, era na verdade filho de Bela II, Rei da Hungria, e seu príncipe herdeiro. Em 1386 Sarajevo, a capital, caiu sob domínio turco, o qual trouxe consigo o Islamismo e as tradições do Oriente. A província turca da Bósnia tornou-se estrategicamente importante por ser a ponta de lança do Império Otomano nos seus contínuos conflitos com o Império Austríaco e com a República de Veneza. A dominação turca foi longa. Apenas em 1878, com o fim da Guerra Russo-Turca, na qual a Áustria teve participação ativa, foi que a Bósnia e a Herzegóvina deixaram de ser turcas e passaram a ser militarmente ocupadas pelo exército austríaco. Em 7 de outubro de 1908, o território passou a fazer parte oficial do Império Austro-Húngaro.

\section{História e Geopolítica Recentes}

O governo imperial em Viena outorgou à sua Província da BósniaHerzegóvina uma Constituição Provincial que já reconhecia as dificuldades étnicas existentes: o eleitorado subdividia-se em três colégios eleitorais, para bósniosmuçulmanos, bósnios-ortodoxos (sérvios) e bósnios-católicos (croatas), cada qual com direito de eleger um número igual de deputados na assembléia provincial.

A província era, contudo, reivindicada pela Sérvia, a qual havia assegurado sua independência do domínio turco também recentemente e não só desejava abrigar em seu território toda a sua etnia, como também arvorava-se paladina do Pan-Eslavismo, movimento que preconizava a união dos povos eslavos e sua libertação de domínios alienígenas a exemplo dos Impérios Austríaco e Otomano. A Rússia, por sua vez, reforçava as aspirações sérvias e via na bandeira 
do Pan-Eslavismo uma via ideológica de tornar concretas suas antigas aspirações de expandir-se pela Europa Oriental e pelo litoral do Mar Negro, passando a dominar os estreitos do Bósforo e de Dardanelos e garantindo assim sua livre saída ao Mediterrâneo. A expansão comercial marítima russa, sempre restringida pelos gelos do inverno que bloqueiam seus portos no Mar Báltico e no Oceano Ártico, poderia assim vir a florescer. A luta dos sérvios contra os turcos foi apoiada pelos russos. Posteriormente, quando o Império Austro-Húngaro declarou guerra à Sérvia, detonando a Primeira Guerra Mundial, a Rússia posicionou-se ao lado dos sérvios. Fora um nacionalista sérvio exacerbado que, em 28 de janeiro de 1914 assassinara, em Sarajevo, o Arquiduque Franz Ferdinand, da Áustria, evento que serviu de pretexto ao início da guerra.

Com o colapso do Império Austro-Húngaro, ao término da guerra, a Bósnia-Herzegóvina passou ao domínio sérvio, com a fundação do Reino dos Sérvios, Croatas e Eslovenos em outubro de 1918. Príncipes sérvios assumiram o trono em Belgrado e o controle de toda região composta pela Sérvia, Croácia, Eslovênia, Bósnia-Herzegóvina, Macedônia e Montenegro. Pouco depois o país assumiu o nome oficial de Reino da Iugoslávia, palavra esta que significa aproximadamente Terra dos Eslavos do Sul .

Em 1940 a Iugoslávia foi invadida por exércitos alemães e italianos, que depois de enfrentarem pouca resistência, partilharam o país entre si. Sérvia, Bósnia e Macedônia ficaram sob ocupação militar alemã. Eslovênia, Montenegro e a Costa Dálmata sob ocupação militar italiana.

À Croácia foi concedida uma independência nominal. De fato, tornou-se um Estado títere governado com mão de ferro pelo partido fascista local, cujo líder, Ante Pavelic, era fiel discípulo de Adolf Hitler, promovendo na Croácia uma cruel limpeza étnica via assassinatos em massa de indefesas populações judaicas, muçulmanas e sérvias. Dois movimentos guerrilheiros desgastaram as tropas de ocupação alemãs e italianas e as forças de Ante Pavelic: os monarquistas comandados pelo Coronel Dragoljub Mihailovic (o qual havia recebido do Rei Petr II, então no exílio em Londres, o título de ministro da guerra) e os comunistas liderados pelo carismático General Josip Broz Tito. Beneficiando-se da forte motivação ideológica de seus comandados, Tito logo sobrepujou-se a Mihailovic como principal líder da resistência iugoslava. O relevo montanhoso, por outro lado, favorecia as operações guerrilheiras que, com o transcurso da guerra, assumiam 
escalas cada vez maiores, obrigando alemães e italianos a manterem tropas numerosas na Iugoslávia.

A Iugoslávia no entre-guerras e durante a Segunda Guerra Mundial, além de uma colcha de retalhos do ponto de vista étnico, inseria-se num teatro geopolítico maior, cujas tensões afetaram, e afetam até hoje, a evolução dos acontecimentos. Dentre as tensões geopolíticas da época, direta ou indiretamente relacionadas com a Iugoslávia, vale a pena lembrar as seguintes:

a Alemanha acabou por substituir a Áustria em suas posições antisérvias, apoiando sempre os croatas. Por outro lado, tanto a Eslovênia como a Croácia abrigavam vestígios de populações germânicas que deveriam se juntar, segundo Hitler, à Grande Alemanha, o Terceiro Reich de Mil Anos, que pretendia criar.

até a Segunda Guerra, a Itália teve como projeto geopolítico reconstituir parte do antigo Império Romano no Mediterrâneo. Muitas áreas do litoral da Eslovênia e da Croácia eram consideradas partes da Italia Irredenta, isto é, partes da Itália que não estavam sob a soberania italiana. Terminada a Primeira Guerra, a Itália viu-se insatisfeita em relação às suas pretensões territoriais, as quais incluíam toda a Dalmácia (Litoral iugoslavo no Mar Adriático) e extensos domínios no Mar Mediterrâneo, outrora sob controle da República de Veneza. Conseguiu, contudo, criar nos Balcãs uma espécie de Estado-Vassalo, a Albânia, além de obter, no Tratado de Versalhes, a condição de Cidade-Livre para a cidade de Fiume, situada na região fronteiriça entre a Itália e a Iugoslávia. Benito Mussolini ampliou o projeto de recriação do Mare Nostrum romano, anexando oficialmente a Albânia e ampliando suas conquistas africanas, as quais, após a Guerra da Abissínia (Etiópia) viabilizavam pressões e pretensões territoriais sobre o Egito. Durante a Segunda Guerra Mundial, Mussolini pensou ser possível a realização do sonho de uma Itália Imperial. Atacou o Egito a partir da Líbia e a Grécia a partir da Albânia. Somente teve sucesso, contudo, enquanto suas desmotivadas tropas contaram com o auxílio de forças alemãs.

- a Inglaterra sempre teve como principal aliada na região a Grécia, desde os tempos da luta pela independência grega contra os turcos. Nas duas guerras mundiais, os ingleses estiveram ao lado dos gregos e dos sérvios contra os alemães. 
- a França tinha uma política de aproximação com a Europa Oriental, consubstanciada por uma aliança chamada de Pequena Entente que congregava além dela própria a Iugoslávia e a Romênia. Durante a Primeira Guerra esteve ao lado de sérvios e romenos contra alemães e austríacos. Já na Segunda Guerra, continuou ao lado dos sérvios/iugoslavos contra os alemães, mas os romenos passaram para o lado do Eixo.

Voltando à evolução histórica dos acontecimentos, chegamos ao final da Segunda Guerra Mundial com as forças guerrilheiras de Tito já dominando todo o país, fato que possibilitou a fundação da República Popular e Democrática da Iugoslóvia, antes mesmo da chegada às suas fronteiras do Exército Vermelho da União Soviética.

Tito dirigiu a Iugoslávia, com poderes ditatoriais, até sua morte em 1980. Instituiu o regime marxista-leninista, aplacou as tensões nacionalistas e étnicas e no campo externo promoveu o alinhamento da Iugoslávia aos movimentos terceiro-mundistas, mantendo considerável independência em relação à União Soviética.

Os planos desenvolvimentistas de Tito não tiveram porém, o sucesso esperado e a Iugoslávia permanecia como um dos mais pobres e subdesenvolvidos países da Europa. Já nos anos 70, mostrando notável flexibilidade, quando comparado aos líderes brutais da Romênia, Bulgária e Albânia, Tito permitiu a emigração dos iugoslavos, os quais partiram em grandes contingentes com destino à Europa Ocidental à procura de empregos mais bem remunerados.

Foi quando o vendaval histórico de desmontagem dos regimes comunistas e da desagregação da própria União Soviética tomou de surpresa toda a Humanidade. Mesmo aos mais ferrenhos adversários de tais regimes não era previsível que os anseios de prosperidade econômica e de liberdades democráticas demolissem tão rapidamente as instituições marxistas-leninistas ferreamente implantadas a partir de 1918. Não será sem razão que historiadores futuros poderão dizer que o século XX se iniciou, de fato, em 1917 com a Revolução de Outubro na Rússia e terminou, de fato em 1989 com a queda do Muro de Berlim. Em poucos anos, o Movimento Solidariedade tomou corpo e chegou ao poder na Polônia, renunciando aos princípios da Ditadura do Proletariado apregoado pelo regime anterior; a Hungria seguiu a mesma trilha por reforma constitucional; a Alemanha Oriental, abandonada pela União Soviética, dissolveu-se pelo clamor de sua 
população unindo-se à Ocidental; a Tchecoslováquia teve sua Revolução de Veludo com transição pacífica e sem traumas para a livre-iniciativa econômica e divórcio político entre tchecos e eslovacos; a Romênia fuzilou o tirano Nicolau Ceausescu via processo sumário à frente de câmaras de televisão; a Bulgária iniciou transição gradual sob liderança dos próprios membros do seu Partido Comunista; a Albânia teve que revisar rapidamente seus dogmas stalinistas, quando sua população empobrecida e desesperada lançou-se ao mar em todos os tipos de embarcações na tentativa de alcançar a Itália do outro lado do Mar Jônico; a China, embora sem avanços democráticos, passou a marchar celeremente na transição para o capitalismo e outras nações asiáticas, como o Vietnam, o Laos e o Cambodja, seguiram o mesmo caminho. Mais surpreendente ainda foi a desagregação da União Soviética e a independência de suas várias repúblicas. Todo o gradualismo das reformas iniciadas por Mikhail Gorbatchov foi abruptamente interrompido quando a tentativa de um golpe, patrocinado por comunistas ortodoxos, abalou definitivamente a autoridade central de Moscou sobre a União Soviética.

Os líderes iugoslavos encastelados em Belgrado mostraram, ante tal cenário, espantosa miopia. Pretenderam insistir, não só na união iugoslava, como também na manutenção do regime socialista. Os eventos, como não poderiam deixar de ser, escaparam totalmente de seu controle. A Eslovênia declarou-se unilateralmente independente em 1990 e foi logo imitada pela Croácia, pela Macedônia e pela Bósnia. Apenas Montenegro, consciente de sua pequena expressão econômica e populacional, não ousou afrontar a Sérvia e suas previsíveis retaliações. Sérvia e Montenegro mantiveram o nome Iugoslóvia e, após um período de infrutíferas tentativas de reverter o processo de desagregação, passaram a apoiar ostensivamente os movimentos de resistência das comunidades sérvias que se viram alojadas dentro dos territórios da Croácia e da Bósnia. A guerra sérviocroata, pelo controle de extensos territórios no norte da Croácia e na Costa Dálmata, reeditou a barbárie das limpezas étnicas com o confinamento de populações inteiras de aldeias croatas em campos de concentração e deslocamentos forçados para outras áreas. A comunidade internacional reagiu com censura pública e boicote econômico ao governo de Belgrado. A medida foi contudo, tímida e, em grande parte, inócua.

Aproveitando-se da duvidosa oportunidade que a guerra propiciava, por estarem os sérvios ocupadíssimos na Croácia, a comunidade muçulmana da 
Bósnia houve por bem proclamar a independência da República da BósniaHerzegóvina, anunciando direitos iguais para as três etnias residentes em seu território. $O$ resultado não poderia ter sido mais desastroso. Com incrivel rapidez os sérvios-bósnios, fortemente armados pelos arsenais de guerra das antigas ForçasArmadas iugoslavas, ainda sob controle de Belgrado, passaram à ofensiva e, em nome de uma autoproclamada República Sérvia da Bósnia, controlam hoje $70 \%$ do território do país. Os croatas da Bósnia, por sua vez, ora aliam-se aos muçulmanos, ora lutam contra eles, no afã de garantir vantagens territoriais nos $30 \%$ da área remanescente.

A capital Sarajevo, sede do governo muçulmano, foi e está até hoje sitiada pelos sérvios, tendo sofrido penosos bombardeios originários da artilharia de grande calibre, postada nas elevações circunvizinhas. A intervenção de forças da ONU foi inicialmente muito restrita, limitando-se a manter aberto o aeroporto de Saravejo para fins de garantir a continuidade de vôos de socorro humanitário à população sitiada. A barbárie da guerra, cinematograficamente transmitida ao vivo pela televisão no mundo inteiro, tem levantado ondas de indignação geral. Tal fato, associado à intrincada rede de interesses geopolíticos, culminou mais recentemente com o envio de tropas das Nações Unidas, mais numerosas, com a missão de estabilizar as frentes de combate. As forças da OTAN, por outro lado, agindo em nome das Nações Unidas, deslocaram suas esquadras para o Mar Adriático e mantêm aeronaves militares em constante patrulhamento sobre a região.

\section{Diagnóstico Geopolítico}

A guerra violenta que ocorreu na Bósnia, e que permanece inconclusa, reeditou termos há muito julgados sepultados, como "limpezas étnicas" "re-distribuições de comunidades", "re-povoamentos com homogeneidade étnica" "espaços-vitais" e outros. A Confederação, proposta pelos bósnios-muçulmanos, foi e é totalmente inaceitável para os bósnios-sérvios e para os bósnios-croatas. Exigem os dois últimos grupos extensas concessões territoriais e o reconhecimento de limites geográficos claros para suas áreas de controle. Quando antes podiam coabitar uma mesma rua, uma mesma aldeia e uma mesma cidade, querem agora zonas exclusivas para suas próprias etnias, declarando ser insuportável a vizinhança com outras. A resistência dos muçulmanos, feroz, heróica e tenaz, não 
parecia conduzir a resultado algum. O cerco implacável a que foi submetida Sarajevo e outras áreas controladas pelos muçulmanos, sujeitas todas elas a contínuos bombardeios, prognosticava o completo genocídio da comunidade Bósnia-Muçulmana, não fossem as recentes e quase que tardias intervenções das Nações Unidas e das forças da OTAN.

Antes de passarmos a quaisquer tentativas de prognósticos, faz-se necessário voltarmos nossa atenção aos países da região e tentarmos vislumbrar o cenário geopolítico que se apresenta:

- a maior parte da população da Albânia é de religião muçulmana, também como conseqüência da antiga dominação turca, tornando-a particularmente sensível aos acontecimentos na Bósnia. Além disso, há um enclave de maioria albanesa no sul da Sérvia, o Kosovo, o qual torna possível imaginar-se que, mais cedo ou mais tarde, a Albânia poderá intervir nos conflitos iugoslavos.

- por ser muçulmana, a Turquia apóia os bósnios contra os sérvios. Além disso, os turcos possuem inúmeras questões pendentes com os gregos nas ilhas do Mar Egeu e em Chipre.

- a Hungria sempre apoiou os croatas contra os sérvios. Durante a Primeira Guerra, como parte do Império Austro-Húngaro, lutou contra os sérvios. Já na Segunda Guerra, alinhou-se com o Eixo. Além disso, existe uma região de maioria húngara na Sérvia: a Voivodina. Uma presumivel intervenção húngara na Voivodina, para proteger a população de origem húngara, poderá detonar a ressurreição dos sonhos nacionais-expansionistas da Hungria, dentre os quais se inclui a questão da Transilvânia. Esta questão constitui a principal razão pela qual a Romênia sempre se alinha ao lado dos sérvios nos conflitos balcânicos. A Transilvânia é reivindicada pelos húngaros por possuir uma minoria húngara. Durante a Segunda Guerra, a Hungria, com o beneplácito alemão, tomou a Transilvânia da Romênia, a qual foi compensada com territórios soviéticos a leste. Depois da guerra, a União Soviética devolveu a Transilvânia à Romênia, mas exigiu de volta a Bessarábia, que hoje é a República (ex-Soviética) da Moldávia (ou Móldova). Vale a pena ressaltar que quando a Transilvânia está sob domínio romeno, a minoria é húngara, e quando está sob domínio húngaro, a minoria é romena.

- a Grécia possui vários problemas não solucionados com seus vizinhos. A Albânia alega que no norte da Grécia há uma minoria albanesa, 
enquanto que a Grécia afirma que há uma minoria grega no sul da Albânia. Outro problema é o das ilhas do Mar Egeu, além da questão de Chipre, que azeda as relações entre Grécia e Turquia. Outra questão complicada é a da Macedônia. Quando esta se tornou independente da Iugoslávia, os gregos pressionaram a Comunidade Econômica Européia e a ONU a não reconhecê-la. A razão disso era o fato do nome Macedônia ser o mesmo de uma região no norte da Grécia. Segundo os gregos, tal designação poderia acarretar uma eventual reivindicação territorial do novo país sobre essa região grega. As pressões gregas para que o país ao menos mudasse de nome frustraram-se e a Macedônia acabou sendo reconhecida internacionalmente. Recentemente, a Grécia fechou as fronteiras e passou a proibir o trânsito, em seu território, de combustível e de outras mercadorias destinadas à Macedônia.

a Bulgária possui problemas com quase todos os países limítrofes. Os búlgaros sempre ambicionaram a região da Macedônia, ocupando-a nas duas Guerras Mundiais, quando em ambas estiveram ao lado dos alemães. Além disso, um dos projetos geopolíticos búlgaros é o de possuir uma saída para o Mar Egeu, saída essa que efetivamente possuíam antes da Primeira Guerra, tendo sido esse território cedido aos gregos após o armistício. Novamente conquistada durante a ocupação alemã, a saída para o Mar Egeu foi perdida no pós-guerra. Outra questão está relacionada a um território no sul da Romênia chamado Dobrudja, reivindicado pela Bulgária.

Os problemas étnicos internos da Bósnia-Herzegóvina e da exIugoslávia já são de complexidade tal, que tornam difíceis prognosticar, com alguma margem de segurança, os acontecimentos futuros. $\mathrm{O}$ cenário geopolítico circunvizinho, expresso parcialmente pelas questões acima apresentadas, traz outras nuvens de imprevisibilidade ao tema.

O prognóstico pode parecer difícil, porém o diagnóstico nos parece claro e semelhante a uma série de outros conflitos históricos de origem geopolítica $\mathrm{e}$ principalmente étnica:

- a Bósnia é hoje um exemplo típico e perverso daquilo que podemos denominar de impossibilidade geográfica de delimitar Estados e Nações, sem fragmentações de uns ou de outros. São freqüentes as áreas territoriais onde não é possível traçar fronteiras entre Nações sem fragmentar Estados sólidos e importantes e, por outro lado, delimitar Estados economicamente viáveis, 
geograficamente coesos e racionais, sem dividir etnias, ou seja, sem fragmentar Nações.

- para nós brasileiros, cidadãos de um país com fronteiras claramente estabelecidas há muito tempo, é de difícil compreensão que conflitos étnicos possam ocorrer entre habitantes de um mesmo Estado Nacional, assemelhando-se a conflitos tribais característicos de outras épocas. Temos no Brasil uma identificação perfeita entre Estado e Nação. Qualquer pessoa nascida no Brasil, ou seja, dentro dos seus limites territoriais, é imediatamente reconhecida pela Lei e, principalmente, pelo juízo popular comum como brasileiro. Ninguém praticamente põe em dúvida a condição de conterrâneo a qualquer pessoa aqui nascida, tenha ele traços raciais africanos, ameríndios, europeus ou asiáticos, tenha ele qualquer filiação religiosa ou qualquer herança cultural. Nem mesmo em regiões fronteiriças, como em Santana do Livramento no Rio Grande do Sul, separada de Rivera por uma rua, existem dúvidas sobre quem são brasileiros e quem são uruguaios. A fronteira está lá, claramente estabelecida e o critério de nacionalidade é bastante claro. Quem nasce do lado de cá é brasileiro e pronto, não há o que discutir! A Lei diz isso e o povo brasileiro não questiona o critério.

- tal não ocorre na Europa, na África e na Ásia. Alojando civilizações muito mais antigas com histórias muito mais complexas, esses continentes contêm tensões étnicas, culturais, nacionais, religiosas e políticas, que detonam freqüentemente conflitos de extraordinária violência e brutalidade.

- na Europa Central, em particular, sempre foi e continua sendo impossivel separar em Estados independentes as diversas etnias ou nacionalidades. É impossivel, de forma prática, o traçado de fronteiras em muitas áreas, simplesmente porque duas ou mais etnias coabitam uma mesma aldeia, uma mesma cidade, uma mesma rua, um mesmo quarteirão ou até mesmo um mesmo prédio. Ninguém tem dúvida, porém, a qual etnia pertence, a qual nacionalidade. Para um polonês, por exemplo, ser polonês sempre foi ser católico, ter sobrenome polonês e ser praticante de ritos e tradições culturais polonesas, independentemente do local de nascimento ou de existir, ou não, um Estado independente com o nome de Polônia. As fronteiras entre a Polônia e a Alemanha e entre a Polônia e a Rússia sempre foram fluidas, deslocando-se, muitas vezes, para leste e oeste centenas de quilômetros. Não importa, nunca houve dúvidas sobre quem era polonês e sobre quem não era. Acreditamos ser ilustrativo explorar um pouco mais o exemplo 
polonês antes de voltarmos à Bósnia. Assim, quando a Polĉnia voltou a se constituir como uma república independente após a Primeira Guerra Mundial, abrigava dentro de suas fronteiras enormes contingentes populacionais de não-poloneses, principalmente alemães, russos, tchecos, eslovacos, lituanos e judeus. Muito embora a Lei concedesse igualdade de direitos aos nascidos dentro dos limites da nova Polônia, não havia aceitação tácita de tal princípio, ou seja, apesar da Lei, o senso comum da população não reconhecia tal princípio. Os poloneses católicos e de origem familiar polonesa regozijavam-se com a autonomia política recémconquistada e não estavam dispostos a entregar os melhores cargos da administração pública, os postos mais elevados das forças armadas e as melhores oportunidades de ascensão econômica e social a alemães, russos ou judeus. Esses consideravam-se, com razão, cidadãos de segunda classe num Estado estranho e hostil, muito embora estivessem habitando a mesma aldeia ou cidade há várias gerações.

os judeus europeus constituem outro exemplo eloquente da falta de sintonia entre Estados e Nações na história moderna e contemporânea. Os judeus somente vieram a ter plena igualdade de direitos perante a Lei na França em 1791, na Grécia em 1830, na Bélgica em 1831, na Holanda em 1848, na Dinamarca em 1849, na Grã-Bretanha em 1858, no Império Austro-Húngaro em 1866, na Suécia em 1870, na Itália em 1870, na Alemanha em 1871, na Suíça em 1874 e na Noruega em 1891. A aceitação de tal fato, no senso comum popular, não acompanhou, obviamente, as datas indicadas. Em vários destes países ocorreram retrocessos graves em tais direitos durante períodos ditatoriais.

Não foram poucas as ideologias e mesmo as religiões que apregoaram a união dos povos em torno de conceitos supranacionais. $O$ cristianismo teve esta característica muito clara em seus períodos de consolidação. $O$ feudalismo medieval congregava a Europa numa união cristã, que se opunha ao islamismo vindo da África e da Ásia, praticamente anulando ou abafando expressões de identificação nacionais. $\mathrm{O}$ socialismo marxista-leninista preconizava a união de classes como contrapartida às expressões de nacionalismo. Não conseguiu, entretanto, eliminar as rivalidades étnicas e culturais dos vários povos que viveram sob tal sistema, rivalidades que se mantiveram latentes e afloraram intactas tão logo os respectivos Estados se desorganizaram. 


\section{Prognóstico Geopolítico}

Em que pesem as dificuldades, contudo, permitimo-nos levar avante alguns prognósticos e cenários possíveis para a Bósnia-Herzegóvina: o que temos de fato de concreto pela frente? Razões humanitárias promovem as intervenções da ONU e da OTAN na Bósnia? Sim! Porém, não são obviamente as únicas! É imperioso evitar que os muçulmanos encontrem ajuda militar de última hora no Islã, por exemplo. Seria inadmissivel aos países da Aliança Ocidental que os bósnios muçulmanos fossem socorridos pelo regime fundamentalista islâmico do Irã, ou pelo regime belicista do Iraque, ou pelo patrocínio terrorista da Líbia. Mesmo na hipótese da derrota total das forças muçulmanas e da conseqüente partilha da Bósnia-Herzegóvina entre sérvios e croatas, nada impediria que um movimento terrorista de resistência viesse a se manter por décadas futuras, com o apoio material e financeiro dos citados países islâmicos. Cumpre, portanto, aos ocidentais, com a anuência da Rússia, de Boris Yeltsin, encontrar soluções de compromisso entre as partes e evitar, não só o genocídio cruel e inaceitável, como também a dissolução da Bósnia-Herzegóvina como Estado independente, dissolução esta que traria como conseqüência o caos geopolítico e uma nova onda de revisões de fronteiras em toda a região balcânica.

Não é só a Bósnia-Herzegóvina que vive problemas de tensões étnicas internas. Em muitos países europeus e de outros continentes, tais tensões existem e nem por isso ocorrem guerras ou genocídios. Muitas vezes, sistemas democráticos, que asseguram a livre expressão cultural de etnias minoritárias e um grau adequado de autonomia em assuntos internos, permitem a convivência pacífica. Porto Rico, por exemplo, tem referendado democraticamente sua submissão aos Estados Unidos da América, reiteradas vezes. A Catalunha, após um período de acentuada expressão de nacionalismo, parece aquietar-se no seio do Reino de Espanha, após ter conquistado direitos específicos na distribuição de recursos tributários e na autogestão de seus assuntos domésticos. Mesmo nos Países Bascos, que abrigam o movimento terrorista ETA, a manifestação democrática e legítima de seus habitantes tem conduzido, aos governos provinciais e às Cortes em Madri, políticos moderados e favoráveis a uma solução semelhante à catalã. Nas repúblicas da extinta União Soviética persistem tensões étnicas assustadoras. Nos paises bálticos, por exemplo, o percentual de população russa é muito alto e toda ela se sente 
ameaçada em seus direitos. A situação permanece administrável, contudo, e não se prevê a curto prazo a eclosão de conflitos violentos. Uma acomodação parece mais provável.

Os exemplos anteriores permitem prognosticar que, um plano de ação metódica, patrocinado pela ONU, com o insistente uso de plebiscitos democráticos, área por área, etnia por etnia, com a simultânea desmilitarização, poderá levar a Bósnia-Herzegóvina a uma situação de compromisso confederativo. Um sistema cantonal, tipo suíço, por exemplo, onde o governo central atue mais em funções coordenadoras, não impositivas, teria boas possibilidades de sucesso na Bósnia.

A livre expressão do povo poderá eleger líderes pacifistas e conciliadores que levem o país a soluções semelhantes às apontadas. As ações mais enérgicas que as forças militares da ONU e da OTAN têm demonstrado mais recentemente vem de encontro a esse prognóstico favorável.

A pacificação total e o retorno à harmonia dependerá, contudo, de uma sintonia entre as principais potências mundiais, particularmente entre os EUA e a Rússia. Esta última, embora enfraquecida, continua sendo a mais poderosa potência militar da Europa. A curto prazo, porém, não será de se estranhar se novos períodos de violência descontrolada voltarem a ocorrer na Bósnia-Herzegóvina, com os sérvios matando os ustaches (croatas), os croatas matando os chetniks (sérvios) e ambos concordando em matar os bósnios ... 